\title{
CADERNOS NEGROS: ESCRITA DE COMBATE AO RACISMO
}

\author{
Black notebooks: writing to fight racism
}

\author{
Cláudia dos Santos Gomes \\ https://orcid.org/0000-0001-9791-7429 \\ Universidade Interamericana, Programa de Pós-Graduação em Ciências da Educação, \\ Assunção, Paraguai - universidadeinteramericana@gmail.com
}

Resumo: O presente artigo tem como propósito pensar o trabalho com o gênero textual conto afro-brasileiro através da obra Cadernos Negros $(C N)$, nas aulas de Língua Portuguesa. A ausência de um trabalho de leitura com a Literatura Afro-brasileira, contraria a Lei 11.645/08, que obriga as Instituições Escolares a inserirem em seus currículos a História e Cultura AfroBrasileira e Indígena. A inserção da coletânea $C N$ nas salas de aula, principalmente no Ensino Fundamental, séries finais, possibilitará aos educandos o conhecimento sobre alguns intelectuais afro-brasileiros e suas produções, o estímulo à leitura de contos nos $C N$ e a discussão das temáticas presentes na Literatura Afro-brasileira. Estes contos abordam questões sobre moradia, infância, abandono, preconceito, manifestações culturais, gravidez na adolescência dentre outros temas muito comuns atualmente. Espera-se com a leitura da obra oportunizar discussões mais efetivas sobre racismo e sobre relações etnicorraciais nas salas de aula uma vez que urge a necessidade de ajustarmos nossos currículos escolares às diversas esferas da sociedade.

Palavras-chave: Cadernos Negros. Contos afro-brasileiros. Lei 11.645/08. Educandos. Racismo.

Abstract: The purpose of this article is to think about working with the textual genre AfroBrazilian short story through the work Cadernos Negros $(C N)$, in Portuguese language classes. The absence of a reading work with Afro-Brazilian Literature, contradicts Law 11.645/08, which obliges School Institutions to include Afro-Brazilian and Indigenous History and Culture in their curricula. The insertion of the $C N$ collection in the classrooms, mainly in elementary school, final grades, will enable students to learn about some Afro-Brazilian intellectuals and their productions, stimulate the reading of short stories in the NC and discuss the themes present in Afro Literature-Brazilian. These tales address questions about housing, childhood, abandonment, prejudice, cultural manifestations, teenage pregnancy among other very common topics today. It is hoped with the reading of the work to provide more effective discussions on racism and on ethnic-racial relations in classrooms, as there is an urgent need to adjust our school curricula to the different spheres of society.

Keywords: Black Notebooks. Afro-Brazilian tales. Law 11.645/08. Learners. Racism. 


\section{$O$ racismo em uma sociedade multiétnica}

Muitas são as discussões sobre racismo. No entanto, questionamentos como "ensina-se o que é clorofila às crianças, mas não informa o que é melanina" surgem cada vez mais nas rodas de conversas e nas academias. O Brasil é a segunda Nação negra fora do continente africano, perdendo somente para a Nigéria, mas ainda estamos longe de alcançarmos a verdadeira democracia racial. De acordo Sueli Carneiro (2011), nosso país produziu uma das formas mais perversas e sofisticadas de racismo que existe no mundo. Paradoxo? Com certeza, pois em um país onde as Leis asseguram a igualdade entre todos os povos e o respeito às diferenças nos mais variados aspectos: cultural, religioso e social, a prática nos revela o inverso. Impunidade é o que caracteriza nossa sociedade multiétnica cujo racismo aparece estampado nas "vitrines" sociais, preconceito este que exclui e inviabiliza uma parcela grande do Brasil.

De acordo Silvio Luiz de Almeida (2018, p. 25), racismo é uma "discriminação que tem a raça como fundamento, e que se manifesta por meio de práticas conscientes ou inconscientes que culminam em desvantagens ou privilégios". No entanto, o autor ainda aborda três concepções sobre o racismo: o individualista seria aquele que se apresenta como uma ausência patológica, proveniente de preconceitos; o institucional cujos privilégios e desvantagens são destinados a grupos em razão da raça, regularizando estas ações através do poder e da intimidação; já o estrutural, que de acordo à "normalidade", faz-se presente nas relações sociais, políticas, econômicas e jurídicas (ALMEIDA, 2018).

Assim, independentemente de sua categoria, o racismo é, portanto, cruel, pois não só induz à morte física como também à morte emocional, intelectual e psicológica, esta denominada de suicida, pois o indivíduo recua-se em seu mundo, calando suas vozes e silenciando seus desejos e sua identidade. Por essas e outras razões, o diálogo sobre essa crueldade deve cada vez mais ocupar espaços que antes não ocupava, como principalmente, as nossas salas de aula. Esse diálogo deve fazer parte da rotina escolar, não só para efetivar a Lei 11.645/08, mas, sobretudo, porque, de acordo Miguel Arroyo (2010):

O diálogo tem privilegiado estratégias de combate ao racismo na sociedade e no sistema através de ações educativas. O racismo é visto como um problema cultural, moral, de mentalidades, logo seu combate passa pedagógica e, consequentemente, dar ênfase em intervenções no sistema escolar visto como um dos espaços educativos por excelência, como um espaço pedagógico e cultural, capaz de mudar imaginários, valores, culturas e condutas. (ARROYO, 2010, p. 113).

Nesse sentido, o diálogo é uma ferramenta de suma importância para quebrar silêncios e dar voz àqueles que não tiveram a oportunidade de mostrar-se como ser social e cultural, àqueles que foram/são vítimas de um dos maiores holocaustos da existência humana: a diáspora africana. Assim, ao terem sua cultura negada, perdem sua identidade por representatividade que não os incluem. Esta diáspora que, segundo Stuart Hall (2003):

[...] não é apenas uma viagem de redescoberta, uma viagem de retorno. Não é

"arqueologia". A cultura é uma produção. Tem sua matéria-prima, seus

Anu. Lit., Florianópolis, v. 25, n. 2, p. 187-202, 2020. ISSNe 2175-7917 
recursos, seu "trabalho produtivo". [...] Mas o que esse desvio através de seus passados faz é nos capacitar, nos produzir a nós mesmos de novo, como novos sujeitos. Portanto, não é uma questão do que as tradições fazem de nós, mas daquilo que nós fazemos de nossas tradições (HALL, 2003, p. 44).

Assim, negar a existência do outro em razão dos traços fenótipos é, na verdade, rejeitar a própria história do homem, das sociedades e da diversidade humana.

Compreender o que significa o racismo não é tão difícil. Basta olharmos nossas escolas, os salários dos brancos contra os dos negros, as cadeiras ocupadas nas academias assim como os astros dos cinemas e da televisão. Para Kabengele Munanga (2000, p. 24), "o racismo é uma crença na existência das raças naturalmente hierarquizadas pela relação intrínseca entre o físico e o moral, o físico e o intelecto, o físico e o cultural", para ele, o racismo é abordado a partir da semelhança com a raça, pois,

[...] com base nas relações entre "raça" e "racismo", o racismo seria teoricamente uma ideologia essencialista que postula a divisão da humanidade em grandes grupos chamados raças contrastadas que têm características físicas hereditárias comuns, sendo estas últimas suportes das características psicológicas, morais, intelectuais e estéticas e se situam numa escala de valores desiguais (MUNANGA, 2000, p. 24).

Essa ideologia apresentada pelo autor, revela sutilmente o conceito de raça como elemento de dominação e poder. Este conceito é utilizado nas construções tensas das relações sociais entre os brancos e os negros cujos dominantes não têm nenhum interesse em esconder seu posicionamento racista em relação aos aspectos fenótipos do outro.

\section{O gênero textual conto afro-brasileiro: a vez e a voz dos silenciados}

O presente artigo "Cadernos Negros: escrita de combate ao racismo" surgiu de questionamentos sobre a ausência de uma literatura, nas salas de aula do Ensino Fundamental II, que representasse tão bem aqueles que contribuíram para a construção da nossa identidade nacional e que foram amordaçados por séculos através da exclusão e da marginalização social. Por muito tempo, os intelectuais afro-brasileiros não tiverem "vez", isto é, espaço na sociedade para se expressarem, principalmente, através da literatura; tiveram suas vozes sufocadas, impedidas de revelar os seus sentimentos, desejos, sonhos e angústias como quaisquer outras. É nesse sentido, e por tantas outras razões, que surgiram os $C N$, criados pelo escritor Cuti e pelo ativista e poeta Hugo Ferreira, autores afros, com sentimentos de pertencimento ao universo afro-brasileiro e engajados contra qualquer forma de discriminação do seu povo.

Diante disso, este artigo busca discutir temáticas da literatura através de uma proposta de trabalho com os contos presentes na coleção de modo a promover leitura, discussões e análise de textos escritos com punhos de intelectuais afro-brasileiros. É de suma importância salientar que esse grupo lutou, historicamente, para ser reconhecido como parte de uma sociedade onde as diferenças sejam respeitadas e valorizadas.

O professor Eduardo de Assis Duarte (2011) conceitua a literatura afro-brasileira como 
um processo de criação e recriação da realidade. Já para a escritora Conceição Evaristo (2009), a literatura afro-brasileira apresenta um "sentimento positivo de etnicidade atravessa a textualidade afro-brasileira" (EVARISTO, 2009, p. 19). Assim, a diversidade da nossa sociedade é explorada pela literatura afro-brasileira, pois de acordo Rosemere Ferreira da Silva (2008):

[...] Para falarmos de Literatura afro-brasileira, de suas articulações de sentido com a Literatura brasileira, da maneira como alguns conceitos e determinadas leituras foram ressignificadas neste universo de construções e desconstruções da imagem do afro-brasileiro na sociedade contemporânea, é necessário nomearmos as produções culturais e literárias que buscaram na própria polêmica sobre a existência de uma Literatura negra dar visibilidade cultural e política a uma comunidade, até então, supostamente representada por alguns discursos legitimados socialmente [...] (SILVA, 2008, p. 4).

É, então, neste universo de visibilização da cultura afro-brasileira que os $C N$ se inserem e seguem ao longo dessas quatro décadas. Essa coleção surgiu em 1978 a partir do encontro de oito intelectuais que dividiam os custos. Inicialmente, a obra foi distribuída em poucas livrarias ficando assim restrito o contato através da interação entre os leitores. No entanto, foi muito bem aceita pelo público leitor e, assim, outros volumes foram lançados alternando o gênero poemas e contos. Cada vez mais a coleção foi se aperfeiçoando e envolvendo escritores de várias regiões do Brasil.

Os temas presentes nesses Cadernos envolvem o afro-brasileiro como sujeito individual e coletivo, assim como a inserção social e o resgate da memória cultural. Após mais de quarenta anos de criação da coleção, os $C N$ quase não se distanciaram dos seus propósitos iniciais que

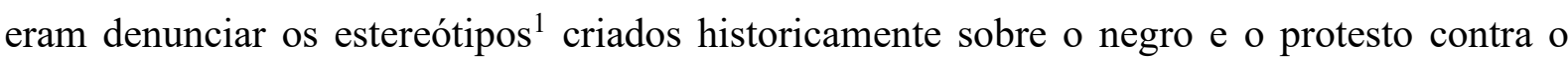
racismo. No volume 3, essa causa está bem expressa nos seguintes versos do poeta Agostinho Neto (1980):

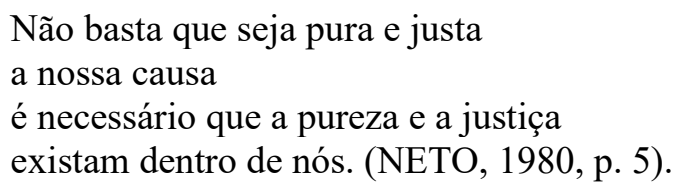

Os organizadores da coleção mantiveram o termo "negro" nos títulos, pois segundo Cuti² (2010, p. 40), o termo "nos remete à reivindicação diante da existência do racismo". Já o termo "afro-brasileiro" para caracterizar os gêneros contos e poemas.

Sendo uma edição anual, os $C N$ publicam poemas nos volumes ímpares e contos nos pares. O primeiro volume foi em formato de "brochura de bolso", tinha somente 52 páginas

\footnotetext{
${ }^{1}$ Conforme Barreto; Araújo; Pereira (2009, p. 35) "Consiste na generalização e atribuição de valor (na maioria das vezes negativo) a algumas características de um grupo, reduzindo-o a estas características e definindo os "lugares de poder" a serem ocupados. É uma generalização de julgamentos subjetivos feitos em relação a um determinado grupo, impondo-lhes o lugar de inferior e o lugar de incapaz no caso dos estereótipos negativos."

${ }_{2}^{2}$ Pseudônimo de Luís Silva, um dos fundadores da organização literária Quilombhoje e um dos mantenedores dos Cadernos Negros.
} 
com tiragem de apenas mil exemplares. No ano de 1994, o Grupo Quilombhoje passa a se responsabilizar pela edição dos $C N$ que são "depoimentos criativos de uma geração de escritores que reivindica um espaço para a voz negra na vida cultural e literária brasileira" (SOUZA, 2005, p. 113).

Desde então, houve uma desestabilidade dos estereótipos criados ao longo do tempo sobre os afrodescendentes. Assim, as vozes das personagens que representam todo esse massacre literário de silenciamento são percebidas em poemas e contos de autores como Márcio Barbosa, Esmeralda Ribeiro, Cuti, Miriam Alves, Cristiane Sobral, Sacolinha, Conceição Evaristo, Lande Onawale, Décio Vieira, Raquel Almeida dentre tantos outros que lutam, através da arte poética, por um mundo mais justo para todos, como o poema Outras Notícias, de Éle Semog (1998), que nos diz:

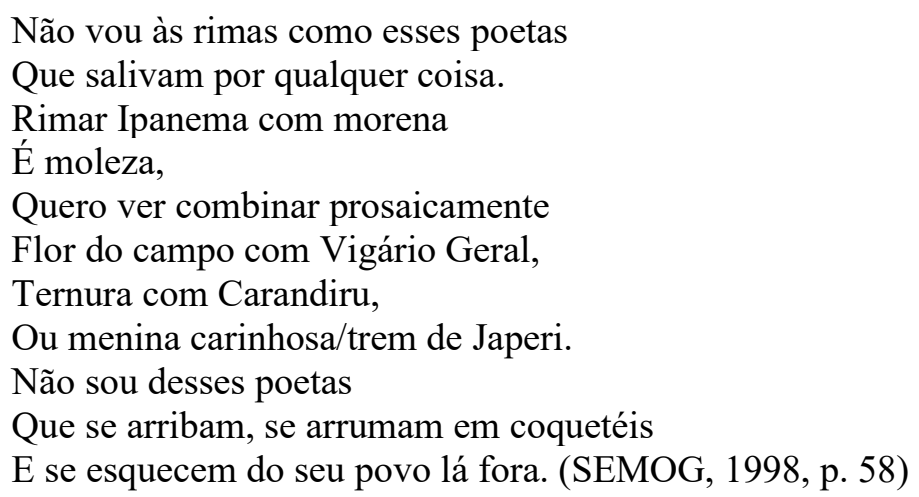

Os $C N$, nesse sentido, apresentam-nos personagens com histórias sobre a vida e as manifestações culturais dos afro-brasileiros através dos contos. Essas personagens representam todos aqueles que formam e fazem parte da nossa sociedade, pois são em sua maioria, os excluídos por suas condições econômicas, culturais, sociais e etnicorraciais. Nesse sentido, a inserção de temas em torno dessas temáticas na literatura foi um passo importante para as discussões sobre preconceito e discriminação racial. Assim, Carlindo Fausto Antônio (2005) que desenvolveu a tese "Cadernos Negros: esboço de análise" nos revela:

No lançamento do primeiro volume dos Cadernos Negros, na cidade de Araraquara, no ano de 1978, no primeiro encontro do Festival Comunitário Negro Zumbi, concretiza-se a retomada de um processo que procurou, ainda na década de 40, rever imagens e enraizamentos impostos pela literatura, pela historiografia, bem como dar visibilidade ao negro, questionando a dimensão de exclusão a que estavam submetidos, entre outros fatores, por um discurso universal branco. Tal universalidade teve implicações na produção literária brasileira, na hierarquização racial dos papéis e na ausência de história e profundidade para personagens e temas negros. (ANTÔNIO, 2005, p. 14).

Os anos 1970, do século XX, foram um período de intensa efervescência de movimentos, encontros e produções para os afro-brasileiros que usaram a escrita para lutar pelas causas sociais, principalmente. Neste período, muitos grupos se reuniam para saborear a arte da palavra, para declamar suas poesias, muitas delas de protesto. Esses grupos vinham de vários 
lugares, logística que Cuti (2010) denominava de "mosaico" por abranger literatos com as mais variadas experiências, como revelam os versos de Clóvis Maciel (1982):

\author{
Retrato \\ O pára-brisa \\ Da minha cabeça é bruma \\ espessa de carapinha \\ planta daninha \\ o nariz chato \\ é o retrato em melanina \\ Negros matizes são os meus pulsos \\ os meus impulsos, minhas raízes, \\ são cicatrizes no meu viver... (MACIEL, 1982, p. 7)
}

Foi com esse impulso, descrito no cenário da segunda metade do século $\mathrm{XX}$, que surgiram os $C N$, cujos participantes eram, em sua maioria, militantes, grupos de estudantes que faziam parte do movimento de esquerda, que lutavam contra as injustiças sociais recorrendo ao poder do discurso literário e buscavam atrair os leitores utilizando-se de uma linguagem persuasiva que, segundo Souza (2005), são escritos por quem assume "o papel de guardião da memória" (2005, p. 84). Essa valorização da tecitura dos $C N$ é abordada por Fonseca (2006) ao afirmar que:

Os autores dos Cadernos Negros buscaram dar visibilidade à sua produção e ampliaram a reflexão sobre a condição de trabalho dos escritores negros, sobre a circulação de seus textos, a marginalidade dessa produção e a linguagem com que se expressam. Numa criação literária mais preocupada com a função social do texto, interessa-lhes, sobretudo, a vida dos excluídos por razões de natureza etnicorracial. A relação entre cor e exclusão passa a ser recorrente na produção literária denominada pela crítica como negra ou afro-brasileira. (FONSECA, 2006, p. 17).

Assim, o conto afro-brasileiro, gênero escolhido para as atividades, possibilitará aos educandos o contato com escritores afro-brasileiros cujas vozes são marcadas por lutas e vitórias em uma sociedade historicamente preconceituosa e excludente.

Diante das barreiras raciais que promovem os diálogos sobre os direitos dos cidadãos em busca de uma sociedade igualitária, percebemos o choque de realidades enraizadas historicamente por preconceitos raciais gerados na sociedade. Nesse sentido, a introdução e discussão das diversas temáticas presentes nos contos afro-brasileiros, no âmbito educacional, é de suma importância para provocar àqueles que ainda mostram resistência para a aceitação das diversidades cultural e racial que formaram nossa sociedade. Sobre isso, a Lei 11.645/08 veio trazer a obrigatoriedade das discussões acerca da História e da Cultura dos Africanos e dos Afro-Brasileiros, além das discussões em torno dos indígenas, nos contextos escolares rompendo o silêncio que por muito tempo esteve presente na sociedade brasileira.

É nítido o reconhecimento da ausência da literatura voltada para a vida dos afrobrasileiros nas salas de aula, visto que o preconceito e o racismo ainda são muito presentes em 
nossa realidade. Infelizmente, muitos educadores mostram o desinteresse pelo tema, talvez por não terem condições de levar para a sala de aula a discussão sobre negritude ${ }^{3}$, talvez por medo de mexer com "algo" que aparentemente não existe.

No entanto, a proposta de trabalho em sala de aula com os contos afro-brasileiros romperá, se bem trabalhado, com esse silêncio em torno da temática negritude. Apresentar os contos dos Cadernos Negros é de grande relevância para essa discussão. A coleção foi fruto de Movimentos Negros que enfrentaram lutas diárias para terem espaço na literatura e nos compêndios didáticos. Portanto, torna-se indispensável o trabalho com os contos afrobrasileiros nas salas de aula possibilitando o resgate histórico-cultural daqueles que representam a formação do povo brasileiro nos mais variados âmbitos os quais a sociedade está inserida.

\section{Cadernos negros: uma proposta de leitura a partir de contos afro-brasileiros}

Os contos afro-brasileiros que compõem a coleção trazem personagens que lutam pelo direito de existir. De um lado, tem-se a dor das injustiças; do outro, a ironia em desconstruir toda a amargura e estereótipos que envolvem as personagens. São histórias sobre pessoas que acreditam no futuro e em uma vida melhor, homens que se deparam com a morte e que somente nesses momentos descobrem o amor pela família, mulheres que têm seus sentimentos revelados, presidiários que sonham em voltar à sociedade, crianças que tiveram seus sonhos rompidos pela violência social, famílias que perderam tudo em enxurradas, periferias, enfim, são histórias que apresentam não só experiências das personagens, mas que muitas vezes, representam a experiência dos leitores reais.

A integridade das personagens vai sendo revelada aos leitores a cada linha da narrativa. Nesse sentido, trabalhar identidades, negritude em sala de aula, torna o contato do real com o imaginário muito mais passível. Por isso, pensa-se em uma proposta de leitura de contos presentes na coleção Cadernos Negros a fim de oportunizar aos educandos, sujeitos em processo de construção da identidade, o contato com alguns contos que retratam a experiência não só dos autores e personagens, mas também dos leitores que se identificam com as narrativas lidas no âmbito social, político, cultural e ideológico.

\section{Sugestão de atividade: a pele que eu habito}

Esta proposta de atividade será baseada na metodologia sugerida por Rildo Cosson (2014) que envolvem as seguintes etapas: motivação, introdução, leitura e interpretação. Através dessa organização, os encontros sugerem dinamicidade e interação entre os sujeitos, priorizando, assim, a presença do texto literário em sala de aula. O conto escolhido foi Minha Cor, de Raquel Almeida (2007) presente nos $C N 30$. No entanto, o professor poderá adaptar a proposta para outros contos afro-brasileiros. Tempo em média de seis aulas.

\footnotetext{
${ }^{3}$ O termo "negritude" foi usado nesse contexto como sinônimo de orgulho daquele que se aceita ser negro.
} 


\section{$1^{\circ}$ MOMENTO (MOTIVAÇÃO)}

O professor apresentará o portal Quilombhoje aos alunos em sala de aula ou na sala de vídeo. Explicar o neologismo que dá nome ao site; apresentar os Cadernos Negros e alguns dos seus autores. Instigar o seguinte questionamento: que literatura esses Cadernos representam?

\section{$2^{\circ}$ MOMENTO (INTRODUÇÃO)}

Os educandos assistirão a um trecho do filme Ó Paí, Ó (2007), com duração de 02:59 (https://www.youtube.com/watch?v=UB3TvnY1Iuw), dirigido por Monique Gardenberg. Depois de assistirem ao vídeo, os educandos realizarão uma discussão sobre o diálogo entre as personagens Boca (Wagner Moura) e Roque (Lázaro Ramos).

Este diálogo nos remete ao filme $O$ Mercador de Veneza (2004), do diretor Michael Radford, baseado na obra literária do escritor inglês William Shakespeare.

Neste filme, tem-se o discurso de um judeu que revelou indignação, tão quanto Roque, presente na passagem "Um judeu não tem olhos? Um judeu não tem mãos? Órgãos, dimensões, sentidos, afeições, sentimentos? Alimentado da mesma comida, ferido pelas mesmas armas?”, com a mesma ênfase da personagem Roque, discurso de $O$ Mercador de Veneza adaptado em Ó Paí, Ó. Assim, perguntas como “Quem agride?", "Quem se deixa agredir?” e "Palavras ferem como as ações?” serão lançadas para a turma que discutirá, também, os estereótipos acerca dos afro-brasileiros, da discriminação e outros elementos que os educandos identificaram no vídeo.

\section{$3^{\circ}$ MOMENTO (LEITURA)}

Entregar o conto, impresso, Minha Cor, de Raquel Almeida (2007), que será lido pelo professor em voz alta e os educandos serão orientados a acompanharem essa leitura, participando dos questionamentos propostos em algumas passagens, como:

1. O conto inicia-se com a expressão "Acordei cedo" em destaque. Por que será que a personagem acordou cedo naquele dia?

2. Para a personagem, fazer a carteira de identidade marca algo especial. Por quê?

3. "Mãe, que cor é essa?", a pergunta feita pela filha revela quais sentimentos dessa personagem?

4. Por que a personagem ficou confusa com a resposta do seu pai em: “... ou é preto ou é branco?"

5. O que a mulher quis dizer com "Você é da cor?"

6. Como a personagem reagiu com essa fala? 
7. Que humilhações são essas pelas quais o pai passou? Por que você acha isso?

8. A palavra "livre" refere-se a quê?

9. Por que será que a personagem nunca mais questionou a sua cor?

10. Por que a personagem diz que os direitos um dia foram negados?

11. A personagem aceita a cor parda? Por quê?

\section{$4^{\circ}$ MOMENTO (INTERPRETAÇÃO)}

Nesta etapa, os educandos interpretarão o conto assim como identificarão os elementos da narrativa. Momento ímpar para abordar o gênero conto. Logo a seguir, a turma, sentados em círculo, socializarão as seguintes perguntas:

1. Quem são as personagens do conto Minha Cor?

2. Quem é o narrador? Personagem ou observador?

3. Onde se passa a história?

4. Em que tempo acontece a história do conto?

5. Como ocorreu o conflito da personagem do conto?

6. O desfecho do conto foi esperado ou inesperado? Por quê?

7. Que fatores sociais são abordados?

8. O conto Minha Cor dialoga com o trecho de Ó Paí, Ó? Se sim, em quais aspectos?

9. Como podemos relacionar a história lida com nossa realidade? Sua realidade?

Caso o professor tenha disponibilidade e ache viável, essa atividade poderá se expandir com a apreciação do filme "Escritores da Liberdade" para que haja uma analogia entre os escritores dos $C N$ com os protagonistas do filme. Outras intervenções podem surgir de acordo o desenvolvimento das atividades.

\section{A literatura afro-brasileira: panorama de lutas e conquistas}

Os educandos têm seu primeiro contato com as literaturas com finalidades didáticas na escola. Muitas vezes, a literatura apresentada traz temas voltados para realidades distantes, sem atrativos ou significados reais para a maioria dos educandos. Assim, o estudo da literatura se torna enfadonho tanto para os educadores quanto para os educandos, pois para estes, as temáticas que lhes são apresentadas não representam sua cultura, seus valores, suas experiências e sua identidade.

O conceito de identidade na visão dos antropólogos se constitui através das práticas sociais dos sujeitos historicamente construídos. Na literatura, o sentimento de nacionalidade dos sujeitos, muitas vezes, aparece superficialmente. Ainda assim, a vontade por uma literatura escrita não no Brasil, mas por uma literatura brasileira que efetivamente representasse e valorizasse a diversidade cultural nacional era o que mais desejavam os intelectuais afrobrasileiros durante o fazer literário. Esses intelectuais que por muito tempo foram excluídos e 
estigmatizados por pertencerem à etnia negra, lutaram para serem reconhecidos como pessoas culturalmente formadas. De acordo Eduardo de Assis Duarte (2002):

Desde o período colonial, o trabalho dos afro-brasileiros se faz presente em praticamente todos os campos da atividade artística, mas nem sempre obtendo o reconhecimento devido. No caso da Literatura, essa produção sofre ao longo do tempo, impedimentos vários à sua divulgação, a começar pela própria materialização do livro (DUARTE, 2002, p. 47).

Recentemente, nos compêndios escolares, a Literatura Afro-brasileira ${ }^{4}$ aparece de forma sutil, pois não abordam a cultura africana e a afro-brasileira como ocorre com a cultura "dos brancos". Nesse sentido, quando a temática negritude é citada nesses compêndios, destacamse, na maioria das vezes, elementos e personagens em situações subalternas e da comiseração, não oportunizam discussões pertinentes à diversidade cultural e a formação da própria identidade do país. Para Duarte (2002, p. 47), "nossa literatura é uma só, e afinal, somos todos brasileiros".

O pensamento de Duarte (2002) nos traz uma reflexão sobre a expressão "somos todos brasileiros". É nítido a ausência de um trabalho com a Literatura Afro-brasileira nas salas de aulas brasileiras, então, quem são os verdadeiros brasileiros que estão por trás do verbo "somos"? O pronome "nós", implicitamente presente, representa quais sujeitos? Por que a escrita dos intelectuais afro-brasileiros não aparece positivamente na Literatura Brasileira? Estes questionamentos podem ser respondidos se analisarmos a fala da pesquisadora Silva ${ }^{5}$ (2008) que diz:

Para falarmos de literatura afro-brasileira, de suas articulações de sentido com a literatura brasileira, da maneira como alguns conceitos e determinadas leituras foram ressignificadas neste universo de construções e desconstruções da imagem do afro-brasileiro na sociedade contemporânea, é necessário nomearmos as produções culturais a literárias que buscaram na própria polêmica sobre a existência de uma literatura negra dar visibilidade cultural e política a uma comunidade, até então, supostamente representada por alguns discursos legitimados socialmente (SILVA, 2008, p. 4).

Percebe-se através das palavras de Silva (2008), que o discurso validado era o da marginalização, pois excluíam manifestações culturais e artísticas que valorizavam e acendiam a história dos afrodescendentes. O preconceito e a discriminação sobre o negro eram tão marcantes na sociedade que grupos em busca da liberdade de expressão surgiram em várias partes do Brasil: os Movimentos Negros. Para isso, o primeiro passo a ser dado para os

\footnotetext{
${ }^{4}$ A expressão "Afro-brasileiro", segundo Cuti (2010), em seu livro Literatura Negro-Brasileira, refere-se a reflexões dos estudos relativos aos traços culturais de origem africana, independente da presença do indivíduo de pele escura, ou seja, daquele que sofre diretamente as consequências do preconceito racial.

${ }_{5}^{5}$ Pesquisadora que desenvolveu a tese de doutorado "Trajetórias de dois Intelectuais Negros Brasileiros: Abdias Nascimento e Milton Santos". Nesse trabalho, Silva (2010) apresenta uma investigação científica sobre o percurso político e intelectual dos intelectuais negros brasileiros Abdias Nascimento e Milton Santos. Discutir como essas trajetórias foram construídas e, sobretudo, problematizar as representações de intelectuais negros no mundo contemporâneo foram os principais objetivos da pesquisa.
} 
envolvidos com os Movimentos Negros foi o de assumir sua negritude, deixando assim, o lugar de excluídos para pertencerem ao lugar de sujeitos sociais, culturais e historicamente formados. Sobre negritude, Zilá Bernd (1988) apresenta que:

A negritude foi basicamente um movimento que pretendeu provocar uma ruptura com o padrão cultural imposto pelo colonizador como único e universal. Essa revolução, operando um deslocamento de perspectiva, oportunizou a revalorização de outras culturas, como as de origem africana e indígena, que haviam resistido à voragem assimilacionista (BERND, 1988, p. 52 , grifos do autor).

Desse modo, (re)valorizar as culturas enraizadas na sociedade através do rompimento com as ideologias do passado, ideologias essas que excluíam toda e qualquer manifestação cultural dos negros, e a luta pela valorização da escrita literária influenciaram os escritores do Jornal do $M N U$ e dos $C N$ a assumiram a voz e a experiência daqueles que por muito tempo foram marginalizados. O Jornal do $M N U$ oportuniza discussões sobre o negro como sujeitos políticos e sociais desestabilizando os estereótipos em torno dos afrodescendentes ao longo do tempo. Já os $C N$ têm um olhar preciso para o diálogo com seus leitores usando uma linguagem clara e simples para atingir sua intenção: expressar, discutir e valorizar as várias manifestações em torno da cultura e da vida dos afrodescendentes no Brasil. A pesquisadora Florentina da Silva Souza (2005) em seus estudos sobre esses periódicos diz que o discurso presente neles torna audível a voz daqueles que foram muito tempo silenciados, pois,

Os autores negros assumem, assim, uma função pedagógica e a missão político-cultural de alertar e unir os leitores para avaliação do lugar étnico de onde falam os grupos que constroem ou reelaboram os discursos nacionais [...]. Como afro-brasileiros, os escritores propõem-se a falar do seu lugar étnico-cultural e, a partir dele, sugerem modelos de análise da cultura africana e das relações raciais no Brasil. (SOUZA, 2005, p. 13).

Os escritores afro-brasileiros fogem da tradição estética imposta historicamente pelos dominadores dando vida à sua voz através de suas experiências e das lutas pelo reconhecimento de sua identidade. Por muito tempo, a literatura privilegiada nos currículos escolares não despertava o discurso em sala de aula de temas relacionados à negritude. No entanto, em 2003, após longo período de luta dos Movimentos Negros, o Governo Federal sancionou a Lei 10.639/03, modificada em 2008 pela Lei 10.645 que inclui a Cultura Indígena, traz a obrigatoriedade de temas voltados para a Cultura Africana e a Cultura Afro-Brasileira nas Instituições Escolares. Foi um passo importante para a História daqueles que tiveram sua cultura negada. No entanto, os temas relacionados à etnia negra ainda aparecem sutilmente em nossas salas de aula, muitas vezes, o desconhecimento por parte dos educadores da legalidade dessa inserção ainda é muito evidente. Temas como racismo, preconceitos, escravização, diversidade cultural, identidade deverão ter destaques e passarão a formar o currículo escolar. Sobre a inserção desses temas em sala de aula, Cuti (2010) diz que "o autor negro-brasileiro emprega em seus textos para romper com o preconceito existente na produção textual de autores brancos 
é fazer do próprio preconceito e da discriminação racial temas de suas obras" (CUTI, 2010, p. 25). Isso é importante, pois:

As ideologias racistas a esta altura já profundamente enraizadas nos corações e nas mentes das pessoas. E o que ainda é pior: essas ideologias racistas, que dão fundamento aos preconceitos, são introjetadas até mesmo pelos próprios negros, que ou permanecem em um estado de alienação ou decidem parar para reavaliar a situação, o que muitas vezes desencadeia uma verdadeira crise de identidade. (BERND, 1988, p. 14, grifo do autor).

Nesta perspectiva, compreende-se a real necessidade de se discutir os processos de construção da identidade, através da democratização do espaço escolar o qual deverá promover a inserção de uma literatura cujas identidades dos que ali estão inseridos sejam reveladas e valorizadas. Essa crise de identidade negra oportunizará outras reivindicações, como afirma Bernd, para o querer "ser negro" (1988, p. 42), reconhecer-se como negro firmando sua própria identidade que por muito tempo foi negada em territórios culturais. Assim, o discurso literário trará à tona a importância das tradições.

Em Da Diáspora: Identidades e Mediações Culturais, Stuart Hall (2003) apresenta reflexões sobre as implicações do sujeito culturalmente formado. Segundo o autor:

A cultura não é apenas uma viagem de redescoberta, uma viagem de retorno. Não é "arqueologia". A cultura é uma produção. Tem sua matéria-prima, seus recursos, seu "trabalho produtivo". [...] Mas o que esse desvio através de seus passados" faz é nos capacitar, a nos produzir a nós mesmos de novo, como novos sujeitos. Portanto, não é uma questão do que as tradições fazem de nós, mas daquilo que nós fazemos de nossas tradições (HALL, 2003, p. 44).

A literatura, por sua vez, observada através das experiências culturais, políticas e sociais, deve oportunizar aos educandos obras, cujas vozes sejam de intelectuais afro-brasileiros, engajadas em ideologias que representam a vida dos negros em épocas/contextos diferentes. Perceber a importância da inserção da Literatura Afro-brasileira nas aulas de Língua Portuguesa é reconhecer a diversidade cultural existente em seu entorno para que assim, os educandos possam se sentir presentes e participantes do/no processo histórico. Essa literatura de experiência $^{6}$ foi possível por causa de intelectuais que doaram sua voz à sociedade marginalizada. Sobre os intelectuais negros, Silva (2010) diz que eles:

[...] não reivindicam um conhecimento particularizado e específico das tradições negras na diáspora, mas a necessidade de diálogo entre formas distintas de conhecimento, através das quais as tradições negras sejam contempladas. (SILVA, 2010, p. 217).

Assim, nesse sentido, a Literatura Afro-brasileira em sala de aula contemplará, significativamente, as tradições afro-brasileiras que marcaram e marcam a diversidade

\footnotetext{
${ }^{6} \mathrm{O}$ termo "experiência" foi utilizado no contexto para indicar um dos elementos-chave do poder que obras literárias têm de nos colocar no lugar do outro, ver o mundo a partir de seus olhos, despertando assim, a sensibilidade.
} 
sociocultural ao qual o corpo discente está inserido. Falar sobre negritude a partir do gênero textual contos presentes nos $C N$ é inserir uma proposta didática que favoreça a (re) construção afirmativa da identidade afro-brasileira por proporcionar através da leitura, a introdução e a discussão pertinentes à negritude, desde os seus aspectos culturais aos seus aspectos políticos e sociais.

\section{Considerações finais}

Com a obrigatoriedade da inserção dos temas voltados para a História e a Cultura da África e dos Afro-brasileiros através da implantação da Lei 10.645/08, que ampliou a 10.639/03, a escola se torna, efetivamente, um espaço de troca de experiência. E a literatura colabora para deslegitimar os estereótipos criados negativamente ao longo do tempo sobre os negros. Assim, é necessário repensar esta historiografia literária no intuito de ressignificar a história e a cultura daqueles que por muito tempo tiveram sua identidade negada.

Diante de tal necessidade emergente, optamos pelos contos dos $C N$ por ser uma das possíveis produções literárias capazes de resgatar os aspectos pertinentes à vida do negro, assim, através desses Cadernos, as personagens afro-brasileiras apresentadas nessas narrativas são protagonistas de suas experiências, aproximando portanto, as realidades de muitos educandos com as apresentadas nas narrativas.

Diante do exposto, é de suma importância ter o contato com os contos que compõem a série Cadernos Negros, por contribuírem para a ressignificação do afro-brasileiro assim como a valorização das manifestações socioculturais que permeiam a vida daqueles que, por muito tempo, foram excluídos socialmente.

Sendo a escola, então, a agência em que os educandos devem desenvolver suas atividades cognitivas, indo além de um simples espaço de divulgação do conhecimento, ela deve oportunizar as reflexões do conhecimento para que assim, os educandos desenvolvam o senso crítico para que assim, (re) conheçam o meio o qual estão inseridos enquanto sujeitos políticos e sociais.

Discutir racismo e buscar estratégias para combatê-lo é antes de tudo um ato educacional, pois como disse Nelson Mandela (1995, p. 28), "ninguém nasce odiando outra pessoa pela cor de sua pele, ou por sua origem, ou sua religião". Assim, a escola e a literatura, juntas, trazem as ferramentas necessárias para que o indivíduo aprenda a respeitar as diferenças e veja o outro como um ser múltiplo, de valores e de identidades.

A partir do momento em que os educandos se deparam com esses contos afro-brasileiros e que se envolvem nas discussões e reflexões sobre a realidade exposta nas linhas literárias, eles estarão ampliando seu senso crítico através dessas questões sociais e políticas desencadeando assim, o letramento literário, pois para Cuti "Literatura é um fazer humano" (2010, p. 13). Rildo Cosson, diz que "o letramento literário trabalhará sempre com o atual, seja ele contemporâneo ou não. É essa atualidade que gera a facilidade e o interesse dos alunos" (COSSON, 2014, p. 34).

Sendo assim, analisando a literatura afro-brasileira como atual, percebemos a grande 
diversidade de temas que englobam a vida do afro-brasileiro cujos temas favorecerão aos sujeitos-leitores o despertar pela busca de autoconhecimento e da formação enquanto sujeitos críticos, políticos e sociais através, principalmente, das discussões em torno do racismo tão presente, ainda, em nosso contexto atual.

\section{Referências}

ALMEIDA, Raquel. Minha cor. In: RIBEIRO, Esmeralda; BARBOSA, Márcio (Orgs.). Cadernos Negros. Contos afro-brasileiros. São Paulo: Quilombhoje, 2007, p. 185. v. 30.

ALMEIDA, Silvio Luiz de. O que é racismo estrutural? Belo Horizonte: Letramento, 2018.

ANTÔNIO, Carlindo Fausto. Cadernos Negros: esboço de análise. 2005. 262f. Tese (Doutorado em Teoria Literária) - Instituto de Estudos da Linguagem, Universidade Estadual de Campinas, Campinas, 2005.

ARROYO, Miguel. A pedagogia multirracial popular e o sistema escolar. In: GOMES, Nilma Lino. Um olhar além das fronteiras: educação e relações raciais. Belo Horizonte: Autêntica, 2010, p. 111-130.

BARRETO, Andreia; ARAÚJO, Leila; PEREIRA, Maria Elisabete (Orgs.). Gênero e diversidade na escola: formação de professoras/es em gênero, orientação sexual e relações étnico-raciais - livro de conteúdo. Rio de Janeiro: CEPESC; Brasília: SPM, 2009. Disponível em: http://estatico.cnpq.br/portal/premios/2014/ig/pdf/genero_diversidade_escola_2009.pdf. Acesso em: 12 de jun. 2020.

BERND, Zilá. O que é Negritude. São Paulo: Brasiliense, 1988.

BRASIL. Lei $n^{o}$. 10.639, de 9 de janeiro de 2003. Altera a Lei no 9.394, de 20 de dezembro de 1996, que estabelece as diretrizes e bases da educação nacional, para incluir no currículo oficial da Rede de Ensino a obrigatoriedade da temática "História e Cultura Afro-Brasileira", e dá outras providências. Brasília, DF, 2003. Não paginado. Disponível em: http://www.planalto.gov.br/ccivil_03/leis/2003/L10.639.htm. Acesso em: 28 de jun. 2020.

BRASIL. Lei $n^{o} 11.645 / 08,10$ de março de 2008. Altera a Lei 10.639/03. Disponível em: http://www.planalto.gov.br/ccivil_03/_Ato2007-2010/2008/Lei/L11645.htm. Acesso em: 29 de jun. 2020.

CARNEIRO, Sueli. Racismo, sexismo e desigualdade no Brasil. São Paulo: Selo Negro, 2011.

COSSON, Rildo. Letramento literário: teoria e prática. 2. ed., $4^{\mathrm{a}}$ reimp. São Paulo: Contexto, 2014.

CUTI, Luis Silva. Literatura negro-brasileira. São Paulo: Selo Negro, 2010.

DUARTE, Eduardo de Assis. Notas sobre a literatura brasileira afro-descendente. In: SCARPELLI, Marli Fantini; DUARTE, Eduardo de Assis (Orgs.) Poéticas da diversidade. Belo Horizonte: FALE-UFMG, 2002, p. 47-61.

DUARTE, Eduardo de Assis. (Org.). Literatura e afrodescendência no Brasil. Belo Horizonte: Editora da UFMG, 2011. v. 1. 
EVARISTO, Conceição. Literatura negra: uma poética de nossa afro-brasilidade. SCRIPTA, Belo Horizonte, v. 13, n. 25, p. 17-31, 2009. Disponível em: https://www.researchgate.net/publication/267423926_Literatura_negra_uma_poetica_de_noss a_afro-brasilidade. Acesso em: 30 jun. 2020.

FONSECA, Maria Nazareth Soares. Literatura negra, literatura afro-brasileira: como responder à polêmica? In: SOUZA, Forentina; LIMA, Maria Nazaré (Orgs.). Literatura afro-brasileira. Salvador: Centro de Estudos Afro-Orientais. Brasília: Fundação Cultural Palmares, 2006, p. 938.

HALL, Stuart. Da diáspora: identidades e mediações culturais. SOVIK, Liv (Org.). Trad. Adelaine La Guardia Resende et al. Belo horizonte: UFMG; Brasília: Representação da UNESCO no Brasil, 2003, p. 25-54.

MACIEL, Clóvis. Retrato. In: RIBEIRO, Esmeralda; BARBOSA, Márcio (Orgs.). Cadernos Negros. Poemas afro-brasileiros. São Paulo: Quilombhoje, 1982, p. 7. v. 5.

MANDELA, Nelson. Longa Caminhada até a Liberdade. Curitiba: Editora Nossa Cultura, 1995.

MUNANGA, Kabengele. Uma abordagem conceitual das noções de raça, racismo, identidade e etnia. Cadernos Penesb, Rio de Janeiro, n. 5, p. 15-34, 2000.

NETO, Agostinho. Do povo buscamos a força. In: RIBEIRO, Esmeralda; BARBOSA, Márcio (Orgs.). Cadernos Negros. Poemas afro-brasileiros. São Paulo: Quilombhoje, 1980, p. 5. v. 3.

SEMOG, Éle. Cadernos Negros: outras notícias. 1998. Disponível em: http://cadernosnegros2k.blogspot.com.br/. Acesso em: 20 out. 2015.

SILVA, Rosemere Ferreira da. Severo D'Arcelino e a produção textual afro-brasileira. África e Africanidades, Rio de Janeiro, n. 1, maio 2008.

SILVA, Rosemere Ferreira da. Trajetórias de dois intelectuais negros brasileiros: Abdias Nascimento e Milton Santos. 2010. 233 f. Tese (Doutorado em Estudos Étnicos e Africanos) Faculdade de Filosofia e Ciências Humanas, Universidade Federal da Bahia, Salvador, 2010. Disponível em: https://repositorio.ufba.br/ri/bitstream/ri/8585/1/Silva.pdf. Acesso em: 14 jul. 2015.

SOUZA, Florentina da Silva. Afro-descendência em Cadernos Negros e Jornal do MNU. Belo Horizonte: Autêntica, 2005.

\section{NOTAS DE AUTORIA}

Cláudia dos Santos Gomes (rical_fsa@yahoo.com.br) é doutoranda em Ciências da Educação pela Universidad Interamericana (Paraguai). Mestra em Letras pela UNEB (Campus V) pelo Programa do PROFLETRAS. Graduada em Letras Vernáculas pela UEFS. Especializada em Língua Portuguesa: Gramática (UEFS) e em Gestão Escolar (UFBA). Foi aluna especial do Doutorado em Literatura e Cultura na UFBA. É professora de Língua Portuguesa do ensino básico das redes estadual e municipal. É escritora e poetisa. Participou dos Cadernos Negros 39 e em várias outras antologias. 
Como citar esse artigo de acordo com as normas da revista

GOMES, Cláudia dos Santos. Cadernos negros: escrita de combate ao racismo. Anuário de Literatura, Florianópolis, v. 25, n. 2, p. 187-202, 2020.

\section{Contribuição de autoria}

Não se aplica.

\section{Financiamento}

Não se aplica.

Consentimento de uso de imagem

Não se aplica.

Aprovação de comitê de ética em pesquisa

Não se aplica.

\section{Licença de uso}

Este artigo está licenciado sob a Licença Creative Commons CC-BY. Com essa licença você pode compartilhar, adaptar, criar para qualquer fim, desde que atribua a autoria da obra.

\section{Histórico}

Recebido em: 31/03/2020

Revisões requeridas em: 07/05/2020

Aprovado em: 03/07/2020

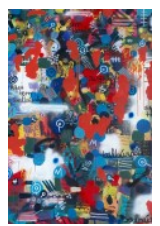

